\title{
Genetic Toxicology
}

National Cancer Institute

\section{Source}

National Cancer Institute. Genetic Toxicology. NCI Thesaurus. Code C18809.

Toxicology focusing on the effects of drugs on genetics material and the generation of mutations and cancer. 